\title{
Negative consequences from heavy social networking in adolescents: The mediating role of fear of missing out
}

\author{
Ursula Oberst $^{\mathrm{a},}$, , Elisa Wegmann ${ }^{\mathrm{b}}$, Benjamin Stodt ${ }^{\mathrm{b}}$, Matthias Brand ${ }^{\mathrm{b}}$, Andrés Chamarro ${ }^{\mathrm{c}}$ \\ ${ }^{a}$ Ramon Llull University, Barcelona, Spain \\ ${ }^{\mathrm{b}}$ General Psychology: Cognition and Center for Behavioral Addiction Research (CeBAR), University of Duisburg-Essen, Germany \\ c Autonomous University, Barcelona, Spain
}

\section{A R T I C L E I N F O}

Article history:

Received 21 July 2016

Received in revised form 16

December 2016

Accepted 19 December 2016

Available online $\mathrm{xxx}$

Keywords:

Social networking sites

Fear of missing out

FOMO

Negative consequences of mobile

device use

Social networking intensity

Adolescents

\begin{abstract}
A B S T R A C T
Social networking sites (SNS) are especially attractive for adolescents, but it has also been shown that these users can suffer from negative psychological consequences when using these sites excessively. We analyze the role of fear of missing out (FOMO) and intensity of SNS use for explaining the link between psychopathological symptoms and negative consequences of SNS use via mobile devices. In an online survey, 1468 Spanish-speaking Latin-American social media users between 16 and 18 years old completed the Hospital Anxiety and Depression Scale (HADS), the Social Networking Intensity scale (SNI), the FOMO scale (FOMOs), and a questionnaire on negative consequences of using SNS via mobile device (CERM). Using structural equation modeling, it was found that both FOMO and SNI mediate the link between psychopathology and CERM, but by different mechanisms. Additionally, for girls, feeling depressed seems to trigger higher SNS involvement. For boys, anxiety triggers higher SNS involvement.
\end{abstract}

(C) 2016 Published by Elsevier Ltd.

\section{Introduction}

Information and communication technologies (ICT) have become an essential part of our lives. The increase in new technologies and virtual communication involving personal computers, tablets, and mobile phones is causing changes in individuals' daily habits and behavior (King et al., 2013). With the rise of ICT, parents and teachers worry more about the possible negative consequences of children's and adolescents' excessive or maladaptive use of these technologies and their applications. Longitudinal studies on Internet addiction show that psychiatric symptoms are important predictors of Internet addiction (Ko, Yen, Chen, Yeh, \& Yen, 2009), especially depressive symptoms (Gámez-Guadix, 2014). In another longitudinal study, frequent real-time online communication, but not e-mailing, was positively related to compulsive Internet use six months after the initial assessment (Van den Eijnden, Meerkerk, Vermulst, Spijkerman, \& Engels, 2008). More recently, Internet-based cell phones (smartphones) and online social networking sites (SNS) have become, together with online video games, the main focus of these concerns.

SNS are defined as web-based virtual communities allowing the construction of an individual and partially public profile. These virtual forums for communication are increasingly present in peoples' daily lives, and although their use is expanding throughout the entire population, they are especially popular among teens and young adults. Facebook, at 1.65 billion users worldwide (Statista, 2016), is the most frequently used platform, followed by Twitter and Instagram. With respect to the younger population, social networking has replaced email and instant messaging as the principal focus of teens' online activity (Garcia,

\footnotetext{
* Corresponding author. Ramon Llull University, Department of Psychology, c/ Císter, 34, 08023, Barcelona, Spain.

Ramon Llull University Department of Psychology c/ Císter, 34 Barcelona 08023 Spain

Email addresses: ursulao@blanquerna.edu (U. Oberst); elisa.wegmann@uni-due.de (E. Wegmann); benjamin.stodt@uni-due.de (B. Stodt); matthias.brand@, uni-due.de (M. Brand); andres.chamarro@uab.es (A. Chamarro)
} 
López-de-Ayala, \& Catalina, 2013), and the age of initial Facebook use is dropping (now 12-13 years). Research has shown that these sites are especially attractive for adolescents because they serve as means to construct their social identities (Oberst, Renau, Chamarro, \& Carbonell, 2016) by allowing them to control their profiles in order to express their desired self-presentation. Via those "virtual selves" they can interact with friends and peers in a forum that is often shielded from supervising adults (Carbonell \& Panova, 2016). Positive effects of social networking are the management and enhancement of social capital (Ellison, Steinfield, \& Lampe, 2007), connectedness with others (Spies Shapiro \& Margolin, 2014), increased self-esteem (Gonzales \& Hancock, 2010), and the satisfaction of their need to belong (Nadkarni \& Hofmann, 2012) in a technologically dominated society.

\subsection{Negative outcomes of maladaptive SNS use in young individuals}

The positive aspects of online social networking notwithstanding, the rewarding nature of this social monitoring may be leading to the emergence of compulsive checking behaviors and excessive engagement in social media, and therefore, to negative psychological consequences. Research has provided clear evidence that overuse or maladaptive use of ICT can have negative effects on the well-being and psychological functioning of children, adolescents, and young adults (Brooks, 2015; Fox \& Moreland, 2015; Kross et al., 2013; Rosen, Whaling, Rab, Carrier, \& Cheever, 2013; Sampasa-Kanyinga \& Lewis, 2015). With respect to SNS, maladaptive use has been identified as a potential mental health problem (Kuss \& Griffiths, 2011). Parents usually worry about their adolescent children being "hooked on Facebook" and spending too much time on SNS and with their smartphones, thus having less involvement with their real-life environment and with school issues. There are several studies showing an association of time spent on SNS and lower grade point averages (Kirschner \& Karpinski, 2010), less connection to peers (Barker, 2009), lower self-esteem (Kalpidou, Costin, \& Morris, 2011), and higher depression (Lin et al., 2016; Pantic et al., 2012). However, the overall time spent on SNS does not seem to be the exclusive factor in maladaptive SNS use (Muench, Hayes, Kuerbis, \& Shao, 2015). Likewise, high social media engagement itself is not considered to be problematic (Turel \& Serenko, 2012). Rather, specific individual vulnerability factors determine the possible negative psychological effects of SNS engagement, such as younger age (Błachnio, Przepiórka, \& Pantic, 2015), distortion of the online profile (Oberst et al., 2016), and existing mental health problems, chiefly depression (Gámez-Guadix, Orue, Smith \& Calvete, 2013). Bhagat (2015) emphasizes that the use of SNS is associated with psychosocial difficulties, such as low self-esteem, but also with mental health problems such as anxiety, depression, and loneliness. The author concludes that Facebook seems to be very attractive for lonely individuals and especially those with psychopathological symptoms. This is in line with other studies that explore the close relationship between SNS use and depression (Błachnio et al., 2015; De Cock et al., 2014; Hong, Huang, Lin, \& Chiu, 2014; Koc \& Gulyagci, 2013). Moreno et al. (2011) show that college students with depressive symptoms are more active on Facebook and are more willing to discuss their problems publicly. The findings suggest that individuals get positive feedback online and receive support from their friends online, which could result in a more public self-presentation. The use of SNS also seems to be related to poor social adaptation, such as social anxiety (Bodroža \& Jovanović, 2016; Ryan \& Xenos, 2011). The results emphasize the relevance of SNS for individuals who try to cope with real life social problems and to gratify social needs online.

However, the direction of this association is often unclear, because existing research on this topic is mostly cross-sectional. It may be that individuals with anxiety and depression tend to use more SNS, or it may also be that those who use social media intensively develop increased depression (Lin et al., 2016). Gámez-Guadix (2014) conducted a longitudinal study of increasing problematic Internet use by adolescents with previous depressive symptoms. His results suggest that previous psychological distress is a risk factor for engagement in problematic online social interactions. An additional finding is that this effect is reciprocal; the use of online social interactions to alleviate distress also contributes to an increase in depression. A recent systematic review (Anderson, Steen, \& Stavropoulos, 2016) highlights that the most tested relationship is the link between mood and anxiety disorders and excessive Internet use. The proposed explanation for this link is that young people seek relationships online to compensate for difficulties in face-to-face relationships by using the Internet as an emotion-regulation strategy. More specifically, a systematic review of quantitative studies revealed that the relationship between online social networking and depressive symptoms is highly complex, and the impact of online social networking on wellbeing can be both positive and negative (Baker \& Algorta, 2016). These authors suggest that the heterogeneous outcomes of these studies are due to underlying mediating and moderating factors. As found in a longitudinal study on problematic Internet use with a Spanish-speaking sample (Gámez-Guadix, Calvete, Orue, \& Las Hayas, 2015), deficient self-regulation, consisting of diminished self-control over cognitions and behaviors related to the Internet, seems to play a key role in the maintenance of problematic Internet use, by increasing the preference of users for online interactions over time.

This is consistent with the results reported by Wegmann, Stodt, and Brand (2015) demonstrating that the link between depression and social anxiety, on one hand, and pathological use of SNS, on the other, is mediated by cognitive factors such as the individual's expectations of SNS use. When psychopathological symptoms exist, individuals may expect that the Internet or SNS will help them escape from negative feelings, experience pleasure, and receive positive feelings. These expectations could enhance the risk of a problematic or addictive use. This study also indicates that the relationship between individual characteristics and problematic use is mediated by specific cognitions, a finding that fits into a theoretical approach of development and maintenance of a specific Internet-use disorder in the I-PACE model (I-PACE stands for Interaction of Person-Affect-Cognition-Execution) by Brand, Young, Laier, Wölfling, and Potenza (2016) and the previous version by Brand, Laier, and Young (2014). 
To summarize, we can identify important risk factors that play a role in the development of problematic use of SNS. However, these risk factors themselves do not necessarily determine the negative psychological outcomes; rather, intervening and mediating variables, such as the fear of missing out construct, could explain this relationship between mental health problems and problematic SNS or smartphone use.

\subsection{The fear of missing out construct}

Fear of missing out (FOMO) is described as “(...) a pervasive apprehension that others might be having rewarding experiences from which one is absent (...)" and "(..) a desire to stay continually connected with what others are doing" (Przybylski, Murayama, DeHaan, \& Gladwell, 2013, p. 1841). Although FOMO is not necessarily a phenomenon exclusive to social media users, individuals with high FOMO might feel compelled to check their social media more often in order to keep up to date on their friends' plans and activities. To date, FOMO has produced more interest in the media than in scientific publications. Although there is still very little literature available on this relatively new construct and its theoretical underpinnings, some scholarly publications showed FOMO to be a mediator variable between personal characteristics and social media engagement. It has been proposed that FOMO could serve as a mediator linking deficits in psychological needs to social media engagement, and FOMO also turned out to be a mediator between different indicators of well-being (need satisfaction, general mood and life satisfaction) and social media engagement (Przybylski et al., 2013). FOMO also mediated the direct relationship between motivational factors and social media engagement in the classroom (Alt, 2015). In a recent study, FOMO has been shown to be a predictor of smartphone addiction (Chotpitayasunondh \& Douglas, 2016). We can conclude that individuals with a low degree of basic need satisfaction (for instance, of connectedness with others) could be more tempted to engage with social media, because SNS, especially when accessed via mobile devices, serve as an easy means of staying in touch with others and participating in their lives (Casale \& Fioravanti, 2015). FOMO would explain the tendency for people with chronic deficits in psychological need satisfaction to constantly seek out updates and possibilities to engage with social media, even when this takes place in potentially inappropriate or dangerous situations, e.g. while driving (Przybylski et al., 2013), attending a lesson (Alt, 2015; Turkle, 2011), or being in a face-to-face conversation (Chotpitayasunondh \& Douglas, 2016). Adolescents with psychopathological problems (especially anxiety and depression) could also develop higher FOMO because of their perceived social deficits. Being connected with and being accepted by one's peers is of utmost importance in adolescence (Desjarlais \& Willoughby, 2010), so SNS are especially attractive for these younger individuals, in order to provide them greater levels of social involvement. By using SNS, these adolescents may be able to satisfy their need to belong, but they also have a higher risk of suffering from anxiety when they have the feeling that they do not belong and that they are missing out on important shared experiences.

\subsection{The present study}

Most studies on negative consequences of technology use investigate these factors in the general population or in young adults, and few studies analyze these mechanisms in individuals below college age (see, Anderson et al., 2016; for a review), despite the fact that they are considered to be the most vulnerable group (Kuss, Griffiths, \& Binder, 2013). Indeed, problematic Internet use in adolescents has become a serious public health problem in some countries, especially in Asia, and studies are being conducted to analyze the multiple factors influencing these maladaptive behaviors, for instance the adolescents' intrapersonal attributes (Li, Newman, Li, \& Zhang, 2016). Except of Asia, there are hardly any studies on this topic using culturally specific adolescent populations, for instance in South America. To fill this gap, our study focuses on the adolescent population in South American countries. Additionally, we analyze the link between psychopathological aspects and negative consequences of smartphone use. Smartphones and other handheld devices with permanent Internet access have revolutionised the way online social interaction is performed; the opportunities to be online have become infinite and represent probably the most recent revolutionary change in the field of ICT. This is because these technologies allow users to access the Internet and Internet applications and communicate with others via social networking whenever and wherever they want. Therefore, behaviors related to the Internet or Internet-based applications, and to the mobile phone can no longer be considered separately, as they represent a single technology that is displayed together (Renau, Gil, Oberst, \& Carbonell, 2015). In the earlier models discussed above (Alt, 2015; Przybylski et al., 2013), FOMO is considered a mediator between personal characteristics or psychological needs and SNS engagement. In our study, we propose a model in which we analyze the relationship between psychopathological symptoms (anxiety and depression) and negative outcomes of mobile device use (smartphone, tablet). We hypothesize that this relationship is mediated by further cognitions such as FOMO. We also consider that the relationship between FOMO and negative outcomes is mediated by the intensity of social network use (see Fig. 1).

\section{Method}

\subsection{Participants}

Participants were 5280 social media users from several Spanish-speaking Latin-American countries who replied to an online questionnaire. Questionnaires with missing answers were eliminated. The data from participants older than 17 and participants 


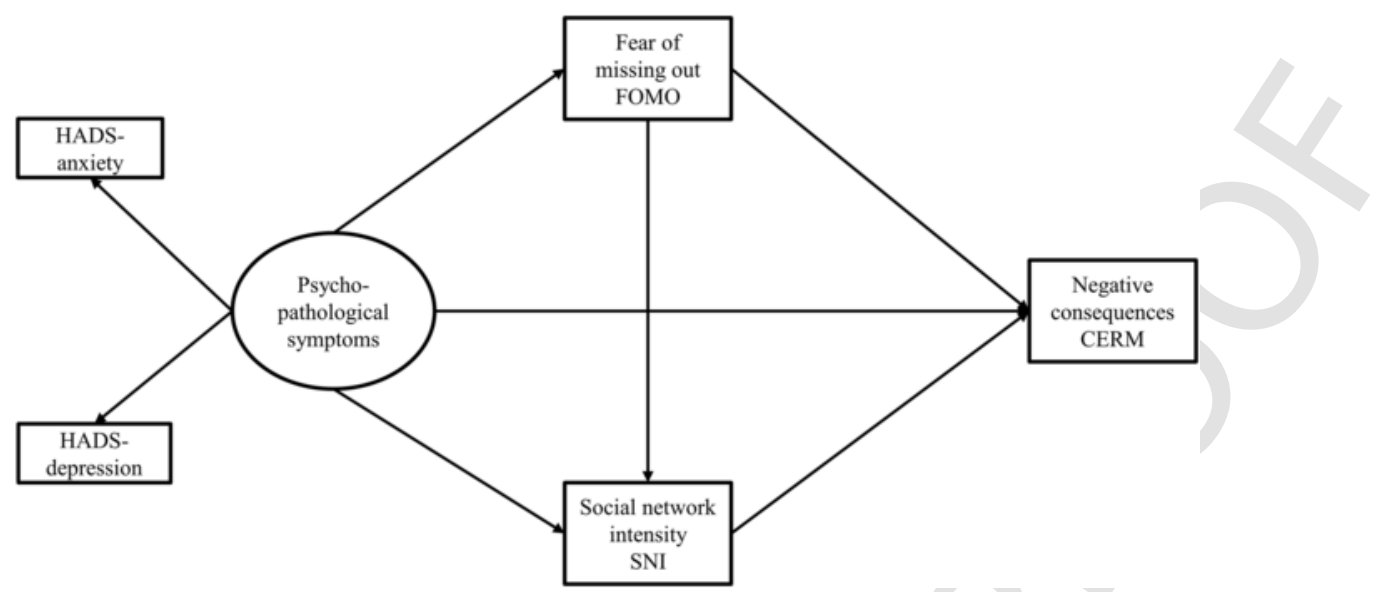

Fig. 1. The hypothesized theoretical model.

from non-Spanish speaking countries or outside Latin America were also not used for this analysis. The final sample consisted of 1468 Spanish-speaking Latin-American social media users (1091 females) between 16 and 18 years of age $(M=16.59, S D=0.62)$ with high educational attainment, as the majority of them reported attending secondary school (90.7\%); the rest reported working or looking for work. The countries of origin with the percentage of participants are detailed in Table 1. Participants reported using an average of 3.5 different SNS ( $S D=1.05)$, with Facebook by far the most used $(99.3 \%)$, followed by WhatsApp $(59.0 \%)$, Twitter (44.2\%), Instagram (35.0\%) and Google plus (35.1\%). The rates of other SNS (Myspace, Ask, Pinterest, Tumblr, Snapchat) were below $10 \%$. According to the participants' self-reports, SNS were used mainly for interacting with others ( $82.9 \%)$, followed by studying (35.8\%), and distraction (12.0\%). Other uses (information seeking, peeking, etc.) were below 10\%.

\subsection{Measures}

Psychopathological symptoms. The self-report Hospital Anxiety and Depression Scale (HADS) in its Spanish version (Quintana et al., 2003) was used. The scale has 14 items, with four response alternatives (different wording depending on the type of item). Lower values indicate stronger presence of symptoms, so the scores were recoded for the analyses, resulting in a system in which higher scores indicate a higher level of symptoms. Cronbach's alpha (see column 4 of Table 2 for all reliability values) of the depression subscale was low and below the convention cutoff scale, but as the Spanish HADS had shown good psychometric properties in different validation studies (see Vallejo, Rivera, Esteve-Vives, Rodríguez-Munoz, \& Grupo, 2012), we decided to use the data.

Fear of Missing Out was assessed using the Spanish translation of the FOMO scale (Gil, Del Valle, Oberst, \& Chamarro, 2015). The Spanish version consists of 10 items to be answered on a 5-point-Likert scale from " $1=$ not at all true of me" to

Table 1

Percentage of subsample from countries (in alphabetical order).

\begin{tabular}{ll}
\hline Country & Percentage \\
\hline Argentina & 1.5 \\
Bolivia & 1.4 \\
Chile & 1.2 \\
Colombia & 9.7 \\
Dominican Republic & 6.3 \\
Ecuador & 7.6 \\
El Salvador & 11.2 \\
Guatemala & 7.4 \\
Honduras & 7.7 \\
México & 3.3 \\
Nicaragua & 5.4 \\
Panama & 1.1 \\
Paraguay & 1.0 \\
Perú & 4.5 \\
Puerto Rico & 0.2 \\
Uruguay & 1.5 \\
Venezuela & 28.4 \\
Total & $\mathbf{1 0 0}$ \\
\hline
\end{tabular}


Table 2

Descriptive statistics and correlations.

\begin{tabular}{llllllll}
\hline Variable & $\mathrm{M}$ & $\mathrm{SD}$ & $\alpha$ & CERM & HADSanx & HADSdep & FOMO \\
\hline CERM & 20.63 & 6.10 & 0.828 & & & & \\
HADS-anx & 7.09 & 3.93 & 00.715 & $0.435^{* *}$ & - & $0.470^{* *}$ & $0.194^{* *}$ \\
HADS-dep & 4.82 & 3.30 & 0.589 & $0.340^{* *}$ & $0.408^{* *}$ & - \\
FOMO & 21.32 & 7.83 & 0.828 & $0.580^{* *}$ & $0.285^{* *}$ & $0.158^{* *}$ \\
SNI & 23.21 & 7.68 & 0.789 & $0.500^{* *}$ & $0.461^{* *}$ \\
\hline
\end{tabular}

Note: ${ }^{* *} p<0.001$.

" 5 = extremely true of me," e.g. "I get worried when I find out my friends are having fun without me"; "I fear others have more rewarding experiences than me" (for the original English scale, see Przybylski et al., 2013).

Social network intensity (SNI) was measured with a short scale drawn from a survey by Salehan and Negahban (2013), consisting of five items, e.g. "Visiting social networking sites is part of my everyday activity," to be answered using a 7-point-Likert scale from " 1 = never" to "7 = always."

To assess the negative consequences of mobile device use, the Spanish Cuestionario de Experiencias Relacionadas con el Móvil [Questionnaire of experiences related to mobile phone use, CERM] (Beranuy, Chamarro, Graner, \& Carbonell, 2009) was used. This instrument consists of 10 items with a 4-point Likert scale, assessing negative outcomes of mobile phone use (e.g. "Have you been at risk of losing an important relationship, job, or academic opportunity due to your mobile phone use?"; "Do you feel that your academic performance has been affected negatively by your mobile phone use?"). Response alternatives were 1-hardly ever, 2-sometimes, 3- frequently, 4- nearly always. For the purpose of this study, the wording of the items was slightly changed, substituting the expression "mobile phone" for "mobile device."

\subsection{Procedure}

The study was approved by the ethics committee of the first author's university. The questionnaire was hosted online at the first author's university with Surveygizmo software and configured such that data collection was anonymous. A Facebook profile on FOMO in Spanish was created (www.facebook.com/spanishFOMO) and linked to several other Facebook profiles and web sites to advertise the study by means of snowball sampling. Participants were invited to join the study online by clicking on a link (www.midetufomo.com; currently deactivated) where participants, after being guaranteed confidentiality and anonymity, gave informed consent by clicking the corresponding button. Then they replied to the questionnaires via their computer or mobile device in their leisure time, which took about 8-10 min. After completing the full questionnaire, participants were given instant feedback on their degree of FOMO on the basis of statistical parameters (mean and quartile).

\subsection{Data analysis}

The statistical standard procedures were performed by using SPSS 21.0 for Windows. Pearson correlations were calculated to test for zero-order relationships between two variables. The structural equation model analysis was computed with MPLUS 6.12 (Muthén \& Muthén, 2011). For the evaluation of the model fits, standard criteria were applied (Hu \& Bentler, 1999): standardized root mean square residuals (SRMR) below a value of .08 indicate good fit of the data; comparative fit indices (CFI/TLI) above .95 indicate an excellent fit, above .90, a good fit; root mean square error of approximation (RMSEA) values below .08 with significance value below .05 indicate acceptable fit.

To determine whether the instruments' concepts and items were equivalent across the different countries and cultures, we controlled the data concerning the reliability of the different constructs. First, all questionnaires were translated and back-translated by native Spanish speakers with a scientific, psychological background who were also fluent in English. These experts helped to reduce potential communication problems concerning the semantic meaning of the items. Second, we calculated reliability using Cronbach's alpha and the Intraclass correlation coefficient, separated by instrument and country (see Harachi, Choi, Abbott, Catalano, \& Bliesner, 2006). In most countries, reliability was acceptable $(\alpha>.700)$ for the different instruments and countries. In six of the seventeen countries (Bolivia, Chile, Dominican Republic, Panama, Paraguay, and Puerto Rico), some of the questionnaires showed lower reliability. In these cases, we repeated the analysis of the structural equation model without these participants (resulting in a sample size of $n=1303$ ), which showed similar effects as the main analysis. Therefore, the criterion of data equivalence was met, since the overall reliability for each instrument was acceptable.

\section{Results}

\subsection{Descriptive statistics and correlations}

The means and standard deviations as well as Cronbach's alphas of all scales are depicted in Table 2. There were significant correlations between all variables (see Table 2). Bivariate statistics revealed no gender differences for any of the dependent vari- 
ables, except that females had higher scores in SNI $(t=-2.19, p=0.028, d f=1466)$; therefore gender was not entered into the main structural equation model. Neither was age, due to the homogeneity of the sample with respect to this variable.

\subsection{Structural equation modeling}

The first proposed theoretical model with "negative outcomes" (CERM) as dependent variable, psychopathological symptoms (HADS) as predictor on a latent level (with the anxiety and depression scales as manifest variables), and with FOMO and SNI as mediating variables, did not yield a sufficient model fit.

Therefore, we decided to use the variables anxiety and depression as an own construct in the model. The revised structural equation model at the latent level was built by using item parceling. In the first step we checked the correlations between all items of the scales and then create two values for each questionnaire. This method allows the reduction of measurement errors. The revised model is shown in Fig. 2.

The revised structural equation model on latent variable with CERM as dependent variable yielded a sufficient model fit. The RMSEA was $.025(p=1.00)$, CFI was .996 , TLI was .993 , and the SRMR was .012 . The $\chi^{2}$ - was also significant; $\chi^{2}$ was 48.55 , $d f$ was $25(p=0.039)$, and $\chi^{2} / d f$ was 1.94 . Overall $60.4 \%$ of the variance in CERM was explained by the full structural equation model $\left(R^{2}=0.604, p<0.001\right)$. The model and all direct as well as indirect effects with factor-loadings and $\beta$-weights are represented in Fig. 2.

The results indicated that HADS-depression had a direct effect on CERM, while HADS-anxiety showed no direct effect. The mediating variables FOMO and SNI also had a direct effect on CERM.

The relationship between HADS-depression and CERM was mediated by FOMO $(\beta=-.071, S E=0.029, p=0.014)$, indicating a partial mediation, but not by SNI $(\beta=0.006, S E=0.014, p=0.660)$. While the relationship between HADS-anxiety and CERM was not significant, FOMO totally mediated this effect $(\beta=0.283, S E=0.035, p<.001)$. SNI was again not a significant mediator of this relationship $(\beta=0.023, S E=0.016, p=0.159)$. Concerning the relationship between FOMO and CERM, this effect was mediated by SNI $(\beta=0.131, S E=0.016, p<.001)$. In the next step, we checked the mediation again and the results showed that the mediation of HADS-depression and CERM by FOMO was also mediated by SNI $(\beta=-.020, \mathrm{SE}=0.008$, $\mathrm{p}<.014)$. A similar pattern was found for the relationship between HADS-anxiety and CERM by FOMO: this relationship was mediated by SNI as well $(\beta=0.081, S E=0.012, p<.001)$.

Because the proportion of female participants was much higher than that of males, and because women scored higher on SNI, the model was tested separately for both genders, using mean structure analysis, showing good model fits $(\mathrm{BIC}=28,874.96$, $\left.\mathrm{RMSEA}=026, p=1.00, \mathrm{CFI}=0.995, \mathrm{TLI}=993, \mathrm{SRMR}=0.018, \chi^{2}=89.34, d f=60, p=0.008\right)$. Overall, the main results were similar to the structural equation model for the whole sample. Interestingly, in the male subsample HADS-depression $(\beta=0.103$, $S E=0.089, p=0.246)$ had no direct effect on CERM, nor a mediation effect by FOMO $(\beta=-.079, S E=0.067, p=0.243)$ or by

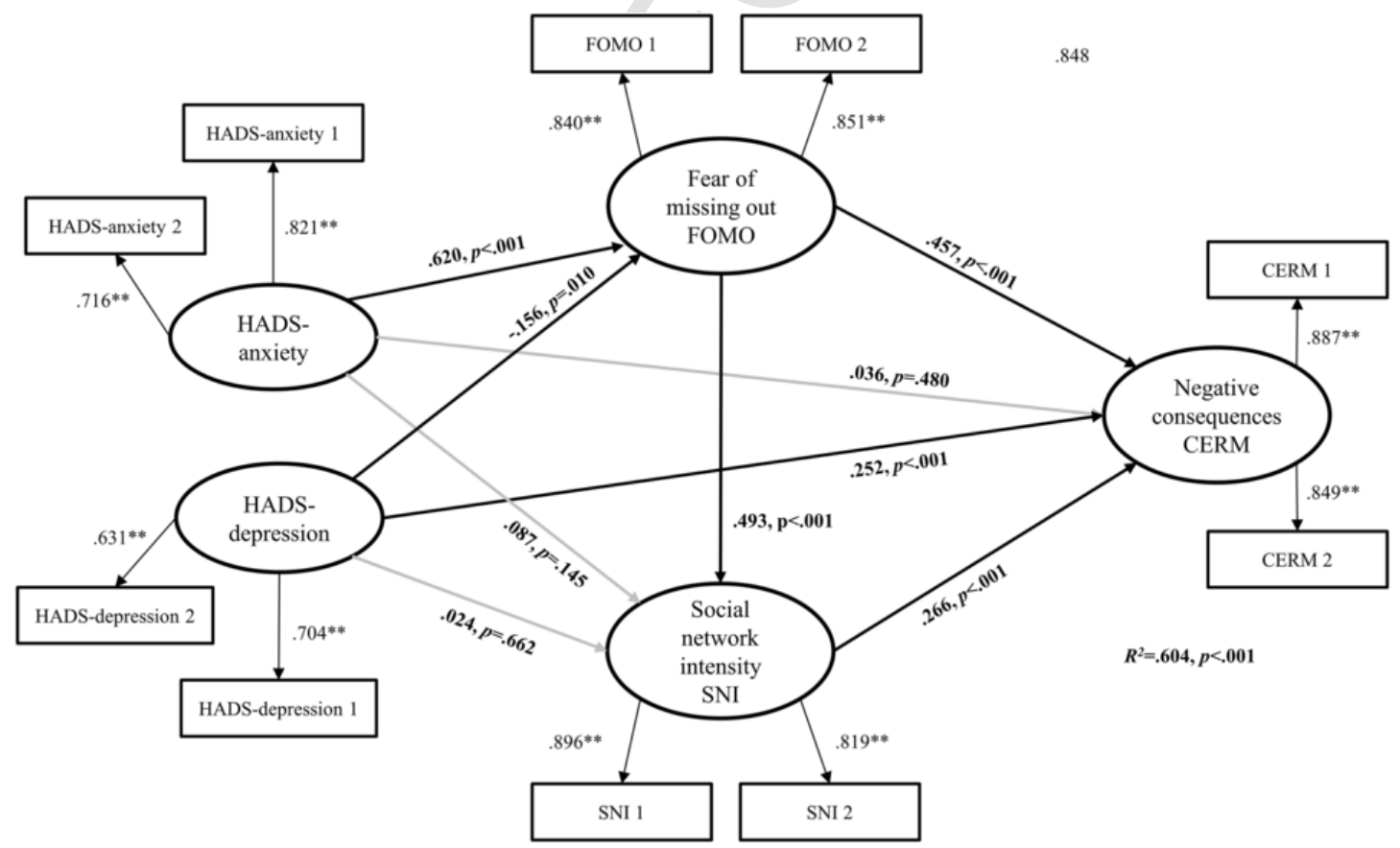

Fig. 2. Results of the revised structural equation model with factor loading, $\beta$-weights, and $p$-values. 
both mediators (FOMO and SNI; $\beta=-.012, S E=0.011, p=0.284$ ). Merely, for females the relationship of HADS-depression and CERM was mediated by FOMO $(\beta=-.063, S E=0.031, p=0.043)$, and HADS-anxiety and CERM was mediated by SNI as well $(\beta=0.047, S E=0.023, p=0.041)$. These latter results have to be taken with caution, due to small effect size in the male group and due to the higher percentage of females in this sample.

\section{Discussion}

The aim of the present study was to determine whether that adolescents with psychopathological problems (especially anxiety and depression) experience negative consequences when using social networking sites (SNS), and that these consequences are mediated by FOMO and the intensity of SNS use.

The main results of this study confirm the role of FOMO in the development of negative consequences of maladaptive technology use in adolescents. In earlier studies, FOMO was found to be a mediator between indicators of well-being and social media engagement (Przybylski et al., 2013) and between motivational factors and social media engagement (Alt, 2015). The results of our study go beyond these previous findings by demonstrating that FOMO mediates the path between psychopathological symptoms and negative consequences of social media use via mobile devices. We have to specify that only depression had a direct effect on negative consequences (CERM), although the effect of both depression and anxiety on the level of experienced negative consequences was mediated by FOMO. This finding may explain why the initially proposed model with psychopathological symptoms as latent variable did not produce adequate model fits.

Additionally, the intensity of social media use has shown not to mediate the relationship between psychopathological symptoms and CERM, but the effect of FOMO to CERM was mediated by social network intensity. The two-fold mediation (psychopathological symptoms - FOMO - SNI - CERM) was confirmed for depression and anxiety as predictor, but this effect, though significant, was very small.

The findings illustrate that in the case of males, depression showed no effect on negative consequences, which were also not mediated by FOMO and SNI. In contrast, in the case of females, psychopathological symptoms were still significant predictors of negative consequences, a finding that contrasts with that of Gámez-Guadix's (2014) study with a Spanish-speaking sample, in which the relationships between depression and problematic Internet use were similar for both boys and girls. This relationship was mediated by FOMO and, for the relationship between anxiety and negative consequences, also mediated by social network intensity. The results point to an important gender difference in adolescence: It is a well-known fact that there is a sharp increase in prevalence rates of female depression during adolescence (Derdikman-Eiron et al., 2012; Salmela-Aro, Upadyaya, Hakkarainen, Lonka, \& Alho, 2016). It might be possible that, for girls, psychopathological symptoms trigger higher involvement in SNS, which is also emphasized by the mediation of anxiety and negative consequences by social network intensity. To our knowledge, there are still few studies on this gender-specific relationship. Nevertheless, the effects are consistent with the results by Ang (2017) emphasizing that females with a stronger Internet habit are more likely to engage in online communication. It leads to the assumption that a higher willingness to be engaged in online communication, especially for female individuals suffering from psychopathological symptoms, leads to a higher risk of experiencing negative consequences due to their use of mobile devices. Additionally, as Simoncic, Kuhlman, Vargas, Houchins, and Lopez-Duran (2014) point out, the relationship between Facebook use and depression is complex. In their own study, Facebook use was unrelated to depressive symptoms among males, whereas among females with high levels of neuroticism, Facebook use seemed to improve depressive symptoms.

Our results build on those of other studies that analyze the processes leading from psychopathology to maladaptive or addictive use of Internet and Internet-based applications (Brand et al., 2014; Gámez-Guadix, 2014). For adolescents with depression, anhedonia and social anxiety, turning to online social interactions may be an easy way to socialize and avoid the disadvantages of face-to-face interactions (Lin et al., 2016). But their diminished sense of self-worth may trigger the continuous rumination and guilt process we have described as fear of missing out. FOMO may be one of the mechanisms implicated in the adolescents' excessive SNS use, along with other specific cognitions and expectancies (Wegmann et al., 2015) that have been identified in research.

Additionally, the results enrich the debate on the addictive use of smartphones and other mobile devices. Smartphones with permanent Internet access and a multitude of Internet-based functions could increase the risks of problematic use, because they remove the demarcation between information and communication (Carbonell, Oberst, \& Beranuy, 2013); people compulsively use their smartphones to check their emails and social networks, play games, listen to music or idly peruse the Internet, whenever not occupied with something else or even in the midst of a face-to-face communicative situation, the latter behavior being called "phubbing" (Chotpitayasunondh \& Douglas, 2016). As Carbonell et al. (2012) argue, the cell phone is becoming a catalyst of FOMO, and hence increases stress and anxiety. Plunging into social networking in order to increase one's feeling of belonging can be a mixed blessing for vulnerable individuals. On one hand, social networking can serve to increase the feeling of need satisfaction. But on the other hand, due to the virtually unlimited sources of information and connections offered by SNS, as their online activity will make them aware of how many other sources for that information exist and are being used by their peers. As a consequence, instead of satisfying the need to belong, increased SNS use may also paradoxically exacerbate the adolescents' perception of missing out on aspects that might be psychologically or practically relevant for them and thus decrease the feeling of need satisfaction. Thus, the use of SNS may actually increase FOMO in a kind of vicious cycle, because the attempt to satisfy the need for connection or belonging by networking online can get users hooked on the reinforcing feelings of 
being "plugged in." Following Einstein's famous quote "The more I learn, the more I realize how much I don't know," this increased SNS activity can produce more feelings of not being connected enough and may result in more social media engagement to try to compensate. Future studies may analyze this specific interaction between SNS use and FOMO.

\subsection{Limitations of the study}

This study has some limitations that are similar to other studies conducted in the field and with online samples: first, the use of a self-selected convenience sample, which is not necessarily representative of all Spanish-speaking or Latin American social media users; second, the use of self-reporting for data selection, so the participants' answers might be subject to biases of social desirability. The unequal gender ratio could also be a limitation of this study. Due to the homogeneous sample, the results cannot be influenced by age variance, which is a strength of this study; however, this may also be a limitation to the generalization of the results for other age groups.

\subsection{Conclusions}

The construct of FOMO has been confirmed to play an important role in the development of maladaptive mobile phone use and its negative consequences for adolescents. It is interesting that in general, the effect of psychopathological symptoms such as depression and anxiety lead to FOMO and to negative consequences of mobile device use, but more so for females. Our results can be taken as a good starting point for using the FOMO scale in studying problematic online social networking and/or problematic smartphone use, and thus contribute to the ongoing debate on the addictive potential of SNS (Andreassen, 2015; Billieux, Philippot, et al., 2015; Billieux, Schimmenti, Khazaal, Maurage, \& Heeren, 2015; Carbonell \& Panova, 2016; Griffiths, Kuss, \& Demetrovics, 2014). Though for the time being, we have to conclude with Carbonell and Panova (2016) that the evidence for social networking as a candidate for a potential behavioral addiction is still scant; however, further studies on FOMO in a framework of SNS addiction may help to shed some light on this issue. Further studies may use different kinds of samples, e.g. clinical samples (individuals diagnosed with Internet addiction), different countries, and different age groups.

There are also some implications for the prevention of addictive behaviors with respect to online social networking and mobile device use. Parents commonly believe that the intensity of social networking (or, generally, the time spent with Internet applications) is the main or sole risk factor for the emergence of negative consequences. However, it is important for them to recognize that psychopathological symptoms play an important role in the development of these outcomes. These symptoms should be addressed first, because they might trigger excessive and maladaptive SNS use. Moreover, adolescents who present FOMO, i.e. who feel that they are absent from their peers' rewarding experiences, are especially at risk, because they might use SNS to compensate for this deficit by excessively trying to be connected with others online. Enhancing their self-esteem and promoting social skills could be an important measure of prevention of negative outcomes of social networking and mobile device use.

\section{Declaration of interest}

The authors report no conflicts of interest.

\section{Acknowledgement}

The authors with to thank Frederic Gil for his help in setting up the online questionnaire.

\section{References}

Alt, D., 2015. College students' academic motivation, media engagement and fear of missing out. Computers in Human Behavior 49, 111-119. http://dx.doi.org/ 10.1016/j.chb.2015.02.057.

Anderson, E.L., Steen, E., Stavropoulos, V., 2016. Internet use and problematic Internet use: A systematic review of longitudinal research trends in adolescence and emergent adulthood. International Journal of Adolescence and Youth 3843 (November), 1-25. http://dx.doi.org/10.1080/02673843.2016.1227716.

Andreassen, C.S., 2015. Online social network site addiction: A comprehensive review. Current Addiction Reports 2 (2), 175-184. http://dx.doi.org/10.1007/ s40429-015-0056-9.

Ang, C.-S., 2017. Internet habit strength and online communication: Exploring gender differences. Computers in Human Behavior 66, 1-6. http://dx.doi.org/10. 1016/j.chb.2016.09.028.

Baker, D.A., Algorta, G.P., 2016. The relationship between online social networking and depression: A systematic review of quantitative studies. Cyberpsychology, Behavior, and Social Networking 19 (11), 638-648. http://dx.doi.org/10.1089/cyber.2016.0206.

Barker, V., 2009. Older adolescents' motivations for social network site use: The influence of gender, group identity, and collective self-esteem. Cyberpsychology \& Behavior: The Impact of the Internet, Multimedia and Virtual Reality on Behavior and Society 12 (2), 209-213. http://dx.doi.org/10.1089/cpb.2008.0228.

Beranuy, M., Chamarro, A., Graner, C., Carbonell, X., 2009. Validación de dos escalas breves para evaluar la adicción a Internet y el abuso de móvil [Validation of two brief scales for Internet addiction and mobile phone problem use]. Psicothema 21, 480-485.

Bhagat, S., 2015. Is Facebook a planet of lonely individuals? A review of literature. The Interrnational Journal of Indian Psychology 3 (1), 5-9.

Billieux, J., Philippot, P., Schmid, C., Maurage, P., De Mol, J., Van der Linden, M., 2015. Is dysfunctional use of the mobile phone a behavioural addiction? Confronting symptom-based versus process-based approaches. Clinical Psychology \& Psychotherapy 22 (5), 460-468. http://dx.doi.org/10.1002/cpp.1910. 
Billieux, J., Schimmenti, A., Khazaal, Y., Maurage, P., Heeren, A., 2015. Are we overpathologizing everyday life? A tenable blueprint for behavioral addiction research. Journal of Behavioral Addictions 4 (3), 119-123. http://dx.doi.org/10.1556/2006.4.2015.009.

Bodroža, B., Jovanović, T., 2016. Validation of the new scale for measuring behaviors of Facebook users: Psycho-social aspects of Facebook use (PSAFU). Computers in Human Behavior 54, 425-435. http://dx.doi.org/10.1016/j.chb.2015.07.032.

Brand, M., Laier, C., Young, K.S., 2014. Internet addiction: Coping styles, expectancies, and treatment implications. Frontiers in Psychology 5 (November), 1256. http://dx.doi.org/10.3389/fpsyg.2014.01256.

Brand, M., Young, K., Laier, C., Wölfling, K., Potenza, M., 2016. Integrating psychological and neurobiological considerations regarding the development and maintenance of specific Internet-use disorders: An Interaction of Person-Affect-Cognition-Execution (I-PACE) model. Neuroscience and Biobehavioral Reviews 71, 252-266. http://dx.doi.org/10.1016/j.neubiorev.2016.08.033.

Brooks, S., 2015. Does personal social media usage affect efficiency and well-being?. Computers in Human Behavior 46, 26-37. http://dx.doi.org/10.1016/j.chb. 2014.12.053.

Błachnio, A., Przepiórka, A., Pantic, I., 2015. Internet use, Facebook intrusion, and depression: Results of a cross-sectional study. European Psychiatry 30 (6), 681-684. http://dx.doi.org/10.1016/j.eurpsy.2015.04.002.

Carbonell, X., Chamarro, A., Griffiths, M., Oberst, U., Cladellas, R., Talarn, A., 2012. Problematic Internet and cell phone use in Spanish teenagers and young students. Anales de Psicología 28, 789-796. http://dx.doi.org/10.6018/analesps.28.3.156061.

Carbonell, X., Oberst, U., Beranuy, M., 2013. The cell phone in the twenty-first century: A risk for addiction or a necessary tool?. In: Miller, P.A. (Ed.), Principles of addiction. Elsevier Academic Press, San Diego, pp. 901-909.

Carbonell, X., Panova, T., 2016. A critical consideration of social networking sites' addiction potential. Addiction Research \& Theory 6359 (July), 1-13. http:// dx.doi.org/10.1080/16066359.2016.1197915

Casale, S., Fioravanti, G., 2015. Satisfying needs through social networking sites: A pathway towards problematic Internet use for socially anxious people?. Addictive Behaviors Reports 1, 34-39. http://dx.doi.org/10.1016/j.abrep.2015.03.008.

Chotpitayasunondh, V., Douglas, K.M., 2016. How "phubbing" becomes the norm: The antecedents and consequences of snubbing via smartphone. Computers in Human Behavior 63, 9-18. http://dx.doi.org/10.1016/j.chb.2016.05.018.

De Cock, R., Vangeel, J., Klein, A., Minotte, P., Rosas, O., Meerkerk, G.-J., 2014. Compulsive use of social networking sites in Belgium: Prevalence, profile, and the role of attitude toward work and school. Cyberpsychology, Behavior and Social Networking 17 (3), 166-171. http://dx.doi.org/10.1089/cyber.2013.0029.

Derdikman-Eiron, R., Indredavik, M.S., Bakken, I.J., Bratberg, G.H., Hjemdal, O., Colton, M., 2012. Gender differences in psychosocial functioning of adolescents with symptoms of anxiety and depression: Longitudinal findings from the Nord-Trøndelag Health Study. Social Psychiatry and Psychiatric Epidemiology 47 (11), 1855-1863. http://dx.doi.org/10.1007/s00127-012-0492-y.

Desjarlais, M., Willoughby, T., 2010. A longitudinal study of the relation between adolescent boys and girls' computer use with friends and friendship quality: Support for the social compensation or the rich-get-richer hypothesis?. Computers in Human Behavior 26, 896-905. http://dx.doi.org/10.1016/j.chb.2010.02. 004.

Ellison, N.B., Steinfield, C., Lampe, C., 2007. The benefits of Facebook "friends": Social capital and college students' use of online social network sites. Journal of Computer-Mediated Communication 12, 1143-1168. http://dx.doi.org/10.1111/j.1083-6101.2007.00367.x.

Fox, J., Moreland, J.J., 2015. The dark side of social networking sites: An exploration of the relational and psychological stressors associated with Facebook use and affordances. Computers in Human Behavior 45, 168-176. http://dx.doi.org/10.1016/j.chb.2014.11.083.

Gámez-Guadix, M., 2014. Depressive symptoms and problematic Internet use among adolescents: Analysis of the longitudinal relationships from the cognitive-behavioral model. Cyberpsychology, Behavior, and Social Networking 17 (11), 714-719. http://dx.doi.org/10.1089/cyber.2014.0226.

Gámez-Guadix, M., Calvete, E., Orue, I., Las Hayas, C., 2015. Problematic Internet use and problematic alcohol use from the cognitive-behavioral model: A longitudinal study among adolescents. Addictive Behaviors 40, 109-114. http://dx.doi.org/10.1016/j.addbeh.2014.09.009.

Gámez-Guadix, M., Orue, I., Smith, P.K., Calvete, E., 2013. Longitudinal and reciprocal relations of cyberbullying with depression, substance use, and problematic internet use among adolescents. Journal of Adolescent Health 53 (4), 446-452. http://dx.doi.org/10.1016/j.jadohealth.2013.03.030.

Garcia, A., López-de-Ayala, M.C., Catalina, B., 2013. The influence of social networks on the adolescents' online practices. Comunicar 41, 195-204. http://dx. doi.org/10.3916/C41-2013-19.

Gil, F., Del Valle, G., Oberst, U., Chamarro, A., 2015. Nuevas tecnologías - ¿ Nuevas patologías? El smartphone y el fear of missing out [New technologies- new pathologies? The smartphone and the fear of missing out]. Aloma 33 (2), 77-83.

Gonzales, A.L., Hancock, J.T., 2010. Mirror, mirror on my Facebook wall: Effects of exposure to Facebook on self-esteem. Cyberpsychology, Behavior and Social Networking 14 (1-2), 79-83. http://dx.doi.org/10.1089/cyber.2009.0411.

Griffiths, M., Kuss, D.J., Demetrovics, Z., 2014. Social networking addiction: An overview of preliminary findings. In: Rosenberg, K.P., Curtiss Feder, L. (Eds.), Behavioral Addictions: Criteria, evidence and treatment. Elsevier, Amsterdam, pp. 119-141.

Harachi, T.W., Choi, Y., Abbott, R.D., Catalano, R.F., Bliesner, S.L., 2006. Examining equivalence of concepts and measures in diverse samples. Prevention Science 7 (4), 359-368. http://dx.doi.org/10.1007/s11121-006-0039-0.

Hong, F.Y., Huang, D.H., Lin, H.Y., Chiu, S.L., 2014. Analysis of the psychological traits, Facebook usage, and Facebook addiction model of Taiwanese university students. Telematics and Informatics 31 (4), 597-606. http://dx.doi.org/10.1016/j.tele.2014.01.001.

Hu, L.T., Bentler, P.M., 1999. Cutoff criteria for fit indexes in covariance structure analysis: Conventional criteria versus new alternatives. Structural Equation Modeling: A Multidisciplinary Journal 6 (1), 1-55.

Kalpidou, M., Costin, D., Morris, J., 2011. The relationship between Facebook and the well-being of undergraduate college students. Cyberpsychology, Behavior and Social Networking 14 (4), 183-189. http://dx.doi.org/10.1089/cyber.2010.0061.

King, A.L.S., Valença, A.M., Silva, A.C.O., Baczynski, T., Carvalho, M.R., Nardi, A.E., 2013. Nomophobia: Dependency on virtual environments or social phobia?. Computers in Human Behavior 29 (1), 140-144. http://dx.doi.org/10.1016/j.chb.2012.07.025.

Kirschner, P.A., Karpinski, A.C., 2010. Facebook and academic performance. Computers in Human Behavior 26 (6), 1237-1245. http://dx.doi.org/10.1016/j.chb. 2010.03.024.

Koc, M., Gulyagci, S., 2013. Facebook addiction among Turkish college students: The role of psychological health, demographic, and usage characteristics. Cyberpsychology, Behavior and Social Networking 16 (4), 279-284. http://dx.doi.org/10.1089/cyber.2012.0249.

Ko, C.H., Yen, J.Y., Chen, C.S., Yeh, Y.C., Yen, C.F., 2009. Predictive values of psychiatric symptoms for Internet addiction in adolescents: A 2-year prospective study. Archives of Pediatrics \& Adolescent Medicine 163 (10), 937-943. http://dx.doi.org/10.1001/archpediatrics.2009.159.

Kross, E., Verduyn, P., Demiralp, E., Park, J., Lee, D.S., Lin, N., ... Ybarra, O., 2013. Facebook use predicts declines in subjective well-being in young adults. PloS One 8 (8), e69841. http://dx.doi.org/10.1371/journal.pone.0069841.

Kuss, D.J., Griffiths, M.D., 2011. Online social networking and addiction- a review of the psychological literature. International Journal of Environmental Research and Public Health 8 (9), 3528-3552. http://dx.doi.org/10.3390/ijerph8093528.

Kuss, D.J., Griffiths, M.D., Binder, J.F., 2013. Internet addiction in students: Prevalence and risk factors. Computers in Human Behavior 29 (3), 959-966. http:// dx.doi.org/10.1016/j.chb.2012.12.024.

Li, X., Newman, J., Li, D.P., Zhang, H., 2016. Temperament and adolescent problematic Internet use: The mediating role of deviant peer affiliation. Computers in Human Behavior 60, 342-350. http://dx.doi.org/10.1016/j.chb.2016.02.075. 
Lin, L.Y., Sidani, J.E., Shensa, A., Radovic, A., Miller, E., Colditz, J.B., ... Primack, B.A., 2016. Association between social media use and depression among U.S. young adults. Depression and Anxiety 33 (4), 323-331. http://dx.doi.org/10.1002/da.22466.

Moreno, M.A., Jelenchick, L.A., Egan, K.G., Cox, E., Young, H., Gannon, K.E., et al., 2011. Feeling bad on facebook: Depression disclosures by college students on a social networking site. Depression and Anxiety 28 (6), 447-455. http://dx.doi.org/10.1002/da.20805.

Muench, F., Hayes, M., Kuerbis, A., Shao, S., 2015. The independent relationship between trouble controlling Facebook use, time spent on the site and distress. Journal of Behavioral Addictions 4 (3), 163-169. http://dx.doi.org/10.1556/2006.4.2015.013.

Muthén, L.K., Muthén, B.O., 2011. Mplus User's guide, 6th ed. Muthén \& Muthén, Los Angeles: CA.

Nadkarni, A., Hofmann, S.G., 2012. Why do people use facebook?. Personality and Individual Differences 52 (3), 243-249. http://dx.doi.org/10.1016/j.paid.2011. 11.007.

Oberst, U., Renau, V., Chamarro, A., Carbonell, X., 2016. Gender stereotypes in Facebook profiles: Are women more female online?. Computers in Human Behavior 60, 559-564. http://dx.doi.org/10.1016/j.chb.2016.02.085.

Pantic, I., Damjanovic, A., Todorovic, J., Topalovic, D., Bojovic-Jovic, D., Ristic, S., et al., 2012. Association between online social networking and depression in high school students: Behavioral physiology viewpoint. Psychiatria Danubina 24 (1), 90-93.

Przybylski, A.K., Murayama, K., DeHaan, C.R., Gladwell, V., 2013. Motivational, emotional, and behavioral correlates of fear of missing out. Computers in Human Behavior 29, 1841-1848. http://dx.doi.org/10.1016/j.chb.2013.02.014.

Quintana, J.M., Padierna, A., Esteban, C., Arostegui, I., Bilbao, A., Ruiz, I., 2003. Evaluation of the psychometric characteristics of the Spanish version of the hospital anxiety and depression Scale. Acta Psychiatrica Scandinavica 107 (3), 216-221. http://dx.doi.org/10.1034/j.1600-0447.2003.00062.x.

Renau, V., Gil, F., Oberst, U., Carbonell, X., 2015. Internet and mobile phone addiction. In: Yan, Z. (Ed.), Encyclopedia of mobile phone behavior. IGI Global, Hershey, PA, pp. 807-817.

Rosen, L.D., Whaling, K., Rab, S., Carrier, L.M., Cheever, N., 2013. Is Facebook creating "iDisorders"? The link between clinical symptoms of psychiatric disorders and technology use, attitudes and anxiety. Computers in Human Behavior 29 (3), 1243-1254. http://dx.doi.org/10.1016/j.chb.2012.11.012.

Ryan, T., Xenos, S., 2011. Who uses Facebook? An investigation into the relationship between the Big Five, shyness, narcissism, loneliness, and Facebook usage. Computers in Human Behavior 27 (5), 1658-1664. http://dx.doi.org/10.1016/j.chb.2011.02.004.

Salehan, M., Negahban, A., 2013. Social networking on smartphones: When mobile phones become addictive. Computers in Human Behavior 29 (6), 2632-2639. http://dx.doi.org/10.1016/j.chb.2013.07.003.

Salmela-Aro, K., Upadyaya, K., Hakkarainen, K., Lonka, K., Alho, K., 2016. The dark side of Internet use: Two longitudinal studies of excessive Internet use, depressive symptoms, school burnout and engagement among Finnish early and late adolescents. Journal of Youth and Adolescence 1-15. http://dx.doi.org/ 10.1007/s10964-016-0494-2.

Sampasa-Kanyinga, H., Lewis, R.F., 2015. Frequent use of social networking sites is associated with poor psychological functioning among children and adolescents. Cyberpsychology, Behavior and Social Networking 18 (7), 380-385. http://dx.doi.org/10.1089/cyber.2015.0055.

Spies Shapiro, L.A., Margolin, G., 2014. Growing up wired: Social networking sites and adolescent psychosocial development. Clinical Child and Family Psychology Review 17 (1), 1-18. http://dx.doi.org/10.1007/s10567-013-0135-1.

Simoncic, T.E., Kuhlman, K.R., Vargas, I., Houchins, S., Lopez-Duran, N.L., 2014. Facebook use and depressive symptomatology: Investigating the role of neuroticism and extraversion in youth. Computers in Human Behavior 40, 1-5. http://dx.doi.org/10.1016/j.chb.2014.07.039.

Statista, 2016. The statistics portal. www.statista.com.

Turel, O., Serenko, A., 2012. The benefits and dangers of enjoyment with social networking websites. European Journal of Information Systems 21 (5), 512-528. http://dx.doi.org/10.1057/ejis.2012.1.

Turkle, S., 2011. Alone together: Why we expect more from technology and less from each other. Basic Books, New York.

Vallejo, M.A., Rivera, J., Esteve-Vives, J., Rodríguez-Munoz, M.F., Grupo, I.C.A.F., 2012. Uso del cuestionario Hospital Anxiety and Depression Scale (HADS) para evaluar la ansiedad y la depresión en pacientes con fibromialgia [Use of the Hospital Anxiety and Depression Scale (HADS) for assessment of anxiety and depression in fibromyalgia patients]. Revista de Psiquiatría y Salud Mental 5 (2), 107-114. http://dx.doi.org/10.1016/j.rpsm.2012.01.003.

Van den Eijnden, R.J., Meerkerk, G.J., Vermulst, A.A., Spijkerman, R., Engels, R.C., 2008. Online communication, compulsive Internet use, and psychosocial well-being among adolescents: A longitudinal study. Developmental Psychology 44 (3), 655. http://dx.doi.org/10.1037/0012-1649.44.3.655.

Wegmann, E., Stodt, B., Brand, M., 2015. Addictive use of social networking sites can be explained by the interaction of Internet use expectancies, Internet literacy, and psychopathological symptoms. Journal of Behavioral Addictions 4 (3), 155-162. http://dx.doi.org/10.1556/2006.4.2015.021. 